indicative of a more sober outlook. The falsely alluring concept of limitlessness which in the last century tempted Americans to embark on a policy of exploitation concurrently with expansion has gone; in certain spheres retreat has followed expansion and many rueful surveys are being made of what has been left, with sound suggestions as to how it may best be used for the future. America wants to reverse the processes by which "man has violated basic arrangements in a manner which Nature will not tolerate". The literature covers a wide range of subjects, including land use, which in this continent is especially bound up with the subject of soil erosion ; forestry and afforestation, important not merely because "almost every one of the forty-eight states is headed towards forest bankruptcy in timber" but also because deforestation has had a terrible sequel in floods, soil wastage and silted rivers. Lists of books on "Oil and Gas Conservation" and "Saving Our minerals" indicate that the future shortage of these vital products has passed from the realm of prophecy to that of serious and calculable prediction. The inclusion of a section on the conservation of wild life serves to show how important is this question, both in and out of the national parks which are of increasing value to the States.

\section{Research at Port Erin, Isle of Man}

THE report of 1937 (No. 50) of the Marine Biological Station at Port Erin, Isle of Man, drawn up by Dr. R. J. Daniel, director, shows the largest number of students using the building in any one year and also the greatest number of visitors to the aquarium. More plaice larvæ have been liberated than during any previous season and there has been the highest percentage survival of lobsterlings in the hatchery. The new Fauna List is now published-a most useful and complete volume-which will be of the greatest assistance to all students. The main work of the Laboratory has been directed towards the breeding of oysters, a research which has now been going on for more than three years. The chief difficulty in obtaining proper spatfalls in the experimental pond is the varying temperature-a very low temperature ruining a promising beginning. To combat such conditions, a number of oysters were kept at a raised temperature-level in the culture house. Some oysters were also kept in dishes in the hatchery and the spawn from these has provided the basis for the limited series of culture-house experiments. These are still going on, and work is maintained in the improvement of methods and feeding of the larvæ in specially adapted vessels.

\section{Announcements}

SIR WIHIIAM Bragg has been elected a foreign associate of the Paris Academy of Sciences in succession to the late L. Torres Quevedo.

Prof. Major Greenwood, professor of epidemiology and vital statistics in the University of London, has been awarded the Bisset Hawkins Gold Medal of the Royal College of Physicians, for his researches in statistics.

THE twelfth International Horticultural Congress will be held in Berlin on August 12-20. After a series of meetings in Berlin, the delegates will visit certain horticultural experimental stations and the chief areas of horticultural production. A visit on August 20 to a Horticultural Exhibition at Essen will bring the Congress to an end. The following delegation has been chosen to represent the British Government at the Congress : Mr. H. V. Taylor, Mr. David Akenhead, Prof. E. E. Cheeseman, Mr. F. Birkinshaw, Mr. F. J. Chittenden, Col. F. R. Durham, Dr. R. G. Hatton, Sir Arthur Hill, Mr. H. J. Holman, Sir Frank Stockdale, Dr. M. A. H. Tincker and Dr. C. W. Wardlaw.

A General Discussion on Luminescence has been arranged by the Faraday Society, and will be held in the Biochemical Laboratory, University of Oxford, on September 15-17. Among the topics to be discussed are various aspects of the luminescence of solids, liquids and gases, and chemiluminescence. As usual in these discussions, a number of distinguished foreign guests have been invited to take part.

The Council of the Harveian Society of London has chosen "The Value of Periodic Medical Examination in the Detection of Disease in Middle Life" as the subject for the Buxton Browne Prize, which consists of a medal and a sum of $£ 100$. The prize is open to any member of the medical profession registered in the British Islez or Dominions, and is limited to candidates less than forty-five years of age. Essays must be sent to the Treasurer of the Society, Mr. Cecil Wakeley, 14 Devonshire Street, W.1, before October 1, 1939.

Mr. Robert L. SACKETT, dean of the School of Engineering at Pennsylvania State College from 1915 until 1937, has been awarded the Lamme Medal of the Society for the Promotion of Engineering Education for achievement in this technical field. $\mathrm{Mr}$. Sackett is the eleventh recipient of the medal provided for in a trust fund created by the late Benjamin Garver Lamme, who was chief engineer of the Westing. house Electric and Manufacturing Co. for twenty-one years prior to his death in 1924. Since his retirement as dean at Pennsylvania State College, Mr. Sackett has devoted himself largely to the work of the Engineering Council for Professional Development. $\mathrm{He}$ has served as president of the Society for the Promotion of Engineering Education and as vice. president of the American Society of Mechanical Engineers.

Erratum. In the letter entitled "Irregular Mitosis and Meiosis induced by Acenaphthene" by Prof. Dontcho Kostoff, in Nature of June 25, p. 1144, the sentence beginning "The viable pollen grains are equal in size ..." should read "The viable pollen grains are unequal in size. . . ." 